\title{
Status of, and conservation recommendations for, the Critically Endangered crested black macaque Macaca nigra in Tangkoko, Indonesia
}

\author{
Juan Francisco Gallardo Palacios, Antje Engelhardt, Muhammad Agil \\ Keith Hodges, Roger Bogia and Matthias Waltert
}

\begin{abstract}
The crested black macaque Macaca nigra, endemic to Sulawesi, Indonesia, is categorized as Critically Endangered on the IUCN Red List and its population in the Tangkoko Nature Reserve is probably the only viable one within its native range. Earlier studies suggested that this population suffered a decline of $75 \%$ during $1978-$ 1994. To evaluate its current status we conducted a line transect survey in the Reserve and assessed effects of ecological and anthropogenic variables on macaque abundance and distribution. We estimated a density of 44.9 individuals $\mathrm{km}^{-2}$ (95\% confidence interval, CI, 25.678.8) and a total population of 1,951 individuals (CI 1,113$3,421)$. This estimate of density is $35 \%$ lower than that of 68.7 individuals $\mathrm{km}^{-2}$ in 1994 . There were moderate to strong correlations between macaque abundance and vegetation structure (basal area and canopy tree density). We observed illegal logging in the area and therefore habitat quality for macaques may be indirectly affected by illegal human activities. If our population estimate is projected linearly $M$. nigra could become extinct in Tangkoko within 46 years, highlighting the urgent need to improve management of illegal hunting and logging in the Reserve.
\end{abstract}

Keywords Crested black macaque, distance sampling, Indonesia, Macaca nigra, primate, Sulawesi, Tangkoko

Juan Francisco Gallardo Palacios* and Matthias Waltert Department of Conservation Biology, Georg-August-University Göttingen, Göttingen, Germany

AntJe Engelhardt ${ }^{\dagger}$ and Keith Hodges (Corresponding author) Reproductive Biology Unit (†Junior Research Group 'Primate Sexual Selection'), German Primate Centre, Kellnerweg 4, 37077 Göttingen, Germany. E-mail khodges@gwdg.de

Muhammad Agil Faculty of Veterinary Medicine, Bogor Agricultural University, Bogor, Indonesia

ROGER BogIA Faculty of Mathematics and Science, Sam Ratulangi University, Manado, North Sulawesi, Indonesia

*Also at: Reproductive Biology Unit, German Primate Centre, Göttingen, Germany

${ }^{\dagger}$ Also at: Courant Research Centre 'Evolution of Social Behaviour', GeorgAugust-University Göttingen, Göttingen, Germany

Received 26 September 2010. Revision requested 14 December 2010. Accepted 19 January 2011. First published online 24 November 2011.

\section{Introduction}

ore than $70 \%$ of Asian primate species are threatened 1 with extinction (IUCN, 2010) and, in Indonesia, which holds the region's greatest primate diversity, $84 \%$ of the species $(>40)$ are threatened. Triggered by human population growth and development, a range of factors including forest fragmentation and loss, changes in vegetation structure and composition (Onderdonk \& Chapman, 2000), and wildlife trade and subsistence, and commercial hunting, are threatening primate survival (Peres, 1990; Lee, 1997; Rosenbaum et al., 1998; Cowlishaw \& Dunbar, 2000; O’Brien \& Kinnaird, 2000; Melfi, 2010).

The future of many primate species depends on their ability to face these threats and adapt to changing conditions (Marsh et al., 1987; Noss \& Csuti, 1994). Monitoring of specific primate populations and the threats to which they are exposed is therefore not only of scientific interest but also important to help decision-makers implement and adapt management actions effectively (Chapman \& Peres, 2001; Rovero \& Struhsaker, 2007; Grow et al., 2010).

Sulawesi, part of the Wallacea biodiversity hotspot, is of particular conservation significance, with up to $98 \%$ of its mammal species, including all primates, being endemic (Whitten et al., 1987). Low sea levels during the middle Pleistocene allowed macaques inhabiting Borneo to reach Sulawesi, where they underwent adaptive radiation that resulted in seven allopatric species $(37 \%$ of all macaque species; Fooden, 1969). Sulawesi macaques are therefore of special importance for our understanding of primate evolution but all are considered threatened (IUCN, 2010), with the Critically Endangered Macaca nigra being at greatest risk of extinction (Supriatna \& Andayani, 2008).

$M$. nigra is currently present on Bacan Island, where it was introduced in 1867 , and in north Sulawesi, its original range, where habitat loss and hunting pressure (monkey meat is a traditional food source) are continuing threats (Bynum et al., 1999; Melfi, 2010). The adjacent TangkokoBatuangus and Duasudara Nature Reserves probably harbour the last viable population of M. nigra within its native range (Rosenbaum et al., 1998; Melfi, 2010). Previous surveys of this population in the 1980 s and 1990s (MacKinnon \& MacKinnon, 1980; Sugardjito et al., 1989; Rosenbaum et al., 1998) suggested a decline of $>75 \%$ within a 16 -year period. Lee (1997) and Rosenbaum et al. (1998) believed commercial 
hunting to be the primary cause of this dramatic decline and suggested that the population could become extinct within 25-50 years.

More than a decade has elapsed since the last of these surveys and we therefore carried out a survey in Tangkoko Nature Reserve in 2009-2010 to update the estimate of the M. nigra population in this area. We also characterized the vegetation of the Reserve, and the degree of anthropogenic disturbance, to examine the influence of these factors on macaque abundance.

\section{Study area}

The Tangkoko-Batuangus/Duasudara Nature Reserves, with a combined area of 8,867 ha, lie in the easternmost tip of the northern arm of Sulawesi (Fig. 1) and span an altitude range of $0-1,351 \mathrm{~m}$. The Reserves include submontane and cloud forests on the summit of Mt Tangkoko (MacKinnon \& MacKinnon, 1980) but the vegetation is broadly classified as lowland tropical rainforest (IUCN, 1991). Three volcanoes dominate the area: Mt Tangkoko, Mt Batuangus and the twin peaks of Duasudara (Fig. 1).
Annual rainfall is $1,550-2,400 \mathrm{~mm}$, with the majority occurring during October-May (O’Brien \& Kinnaird, 1997). Temperatures are relatively constant throughout the year, with a mean monthly minimum of $21.7-23.9^{\circ} \mathrm{C}$ and mean monthly maximum of $29.2-34.4^{\circ} \mathrm{C}$.

Although the Tangkoko-Batuangus/Duasudara Nature Reserves are formally protected, forest destruction and alteration have been occurring for many years. Over a period of less than 2 decades (1979-1994) this Reserve complex was reduced to half its original size, mostly because of illegal establishment of coconut farms (O'Brien \& Kinnaird, 1996). The landscape of the Reserves now includes primary and secondary forest, regenerating abandoned gardens and scrubland/burnt areas.

This study was confined to the 4,450-ha Tangkoko Nature Reserve, which also includes a small area (615 ha) that has been recently given the status of Recreational Park. Compared to Duasudara and Batuangus Nature Reserves the vegetation in Tangkoko remains relatively undisturbed by human activity, although illegal logging takes place on a small scale and several areas have been burnt (c. 150 ha near the village of Batu-Putih and 500 ha in the north of the
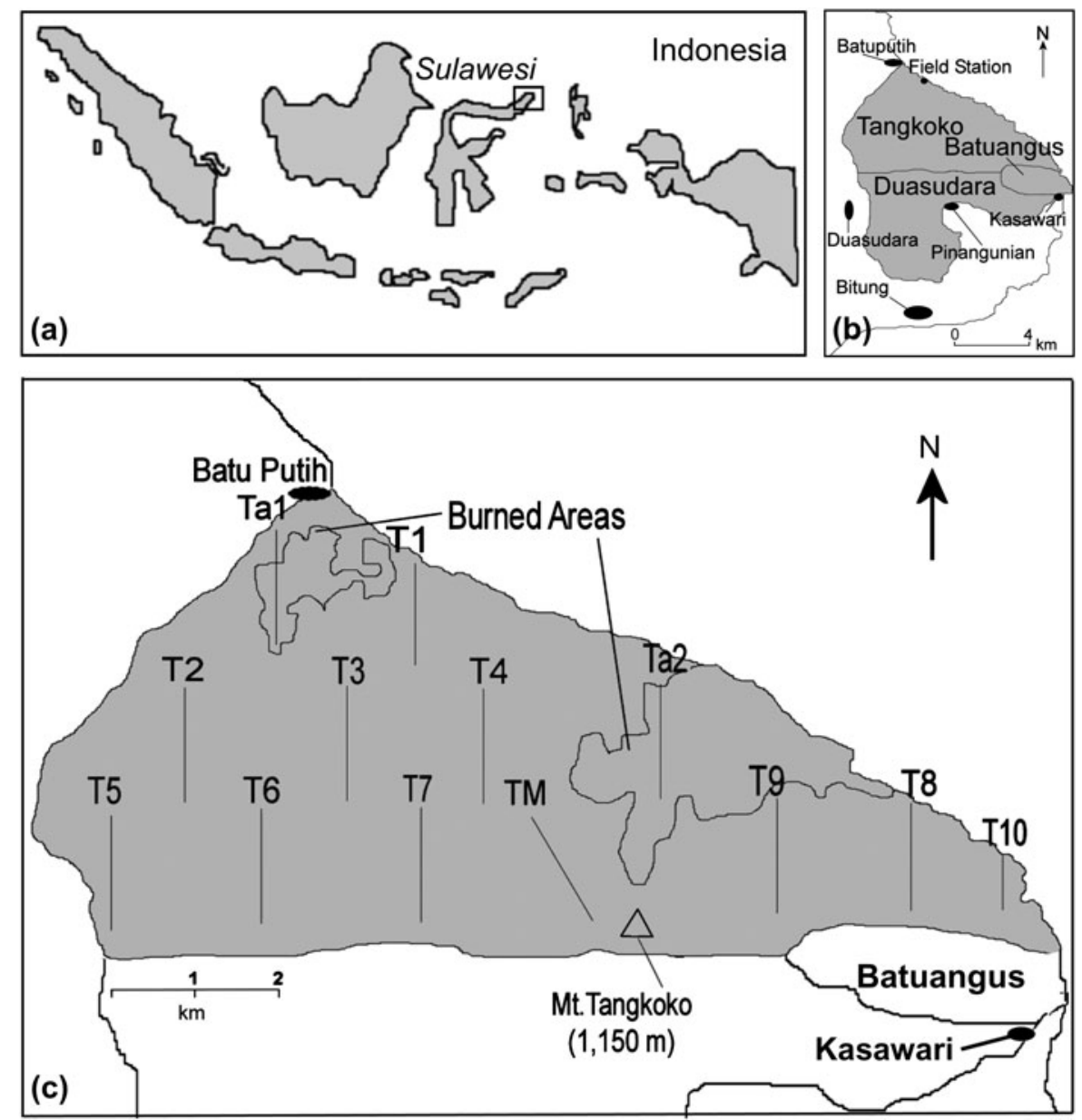

FIG. 1 (a) Location of the study area in north-eastern Sulawesi, and (b) of Tangkoko-Batuangus and Duasudara Nature Reserves, and (c) the locations of the 13 survey transects in Tangkoko Nature Reserve. 
Reserve; Fig. 1). There is a long-term presence of researchers in Tangkoko associated with the Macaca Nigra Project.

\section{Methods}

\section{Line transect survey}

A line transect survey (Buckland et al., 2001) was carried out between October 2009 and March 2010. Sampling was limited to Tangkoko Reserve because $11 \mathrm{~km}$ of reconnaissance walks in the adjacent Duasudara Reserve in September 2009 did not encounter any macaques. The survey was designed following a 2-week pilot study in which a total of nine groups was encountered in a survey effort of $40.4 \mathrm{~km}$. Thirteen transects were located systematically across the study area (Fig. 1) to give a similar coverage of primary and secondary forest, cultivated gardens and burnt areas across altitudes of $0-850 \mathrm{~m}$. Transects $\mathrm{Ta}_{1}, \mathrm{~T}_{1}$ and $\mathrm{T}_{4}$ passed through home ranges of habituated macaque groups. The locations of transects TM and T1o were constrained by the terrain. Transect lengths were 850-1,700 $\mathrm{m}$, with the majority being 1,650 $\mathrm{m}$ long. Since $M$. nigra does not have fixed resting times, and extended resting periods only occur during very hot and dry months (Macaca Nigra Project, unpubl. data), we did not limit our surveys to certain times of the day. Teams of two observers walked 2-4 transects daily; each transect was surveyed on average 11.7 times. For each detection event, perpendicular distance (measured with a laser rangefinder) from the transect to the estimated centre of the group, location on the transect (with a global positioning system, GPS) and group size were measured. Following Peres' (1999) recommendations, transects were walked at an average speed of $1-1.5 \mathrm{~km} \mathrm{~h}^{-1}$, with stops every 50-100 $\mathrm{m}$ to scan the forest and to minimize background noise. Surveys were halted during heavy rain.

\section{Vegetation assessment}

A total of 68 plots of $25 \times 25 \mathrm{~m}$ (0.0625 ha; total 4.25 ha) were distributed along the 13 transects, $250 \mathrm{~m}$ apart. At each plot all trees with a diameter at breast height (DBH) $\geq 10 \mathrm{~cm}$ were identified to species and DBH measured. For trees with buttresses DBH was measured directly above the buttress. Canopy tree density (see below), total basal area (sum of the cross-sectional area at breast height of all tree trunks), mean basal area, Shannon species diversity index $\left(\mathrm{H}^{\prime}=-\sum\right.$ piln $p_{i}$, where $p_{i}$ is the relative abundance of each species) and tree density per plot were calculated. While total basal area is proportional to overall timber stock, mean basal area better reflects tree sizes large enough to serve as important primate food sources (Rovero \& Struhsaker, 2007). In addition, the abundance of Ficus species and Dracontomelum species in a 40-m strip on each side of the transect were recorded separately as these trees are known to be important food resources for M. nigra (O'Brien \& Kinnaird, 1997). As there is usually a strong correlation between tree height and DBH (Leighton \& Leighton, 1982), we defined canopy trees as any tree with a DBH $\geq 30 \mathrm{~cm}$ (see also Whitten et al., 1987; Lee, 1997).

\section{Other variables}

To quantify human disturbance all human signs along the transects were noted. These were categorized as illegal logging (including roads/trails traversing transect), people encountered and traps. The total number of signs per transect was divided by the survey effort (i.e. the total length of the transect) and an anthropogenic disturbance index calculated as the sum of all types of disturbances. For each transect the shortest distance to the nearest village and mean transect altitude were determined using a GPS.

\section{Data analysis}

Sighting data for M. nigra were analysed using Distance v. 5.0 (Thomas et al., 2010). A detection function $g(y)$ was fitted to truncated data to model detection probability. Model selection was based on Akaike information criterion (AIC), $\chi^{2}$ goodness-of-fit and visual estimation. A hazard rate model with cosine expansion was finally selected. Expected group size was estimated by using the size-biased regression method (natural log of group size against estimated detection probability). This corrects for the fact that large groups are more easily detected at greater distances than small groups.

To examine any effect of vegetation parameters on macaque distribution an index of relative macaque abundance was calculated for each transect based on the untruncated encounter rate (number of groups observed per $\mathrm{km}$ ). Spearman rank correlation coefficients corrected with the Benjamini-Hochberg test (Benjamini \& Hochberg, 1995) were calculated to examine correlations between this abundance index and nine of the measured variables. In addition, to identify which measured variables best explained macaque abundance a multiple regression model using relative macaque abundance as response and altitude, mean basal area and canopy tree density as explanatory variables was constructed.

\section{Results}

\section{Macaque density and abundance}

A total survey effort of $220 \mathrm{~km}$ resulted from 62 days of effective surveying. After truncation of distance data to $37.5 \mathrm{~m}$, corresponding to a detection probability of $92 \%, 41$ of 49 detection events were available for modelling detection probability. Groups were of 3-70 individuals (mean 


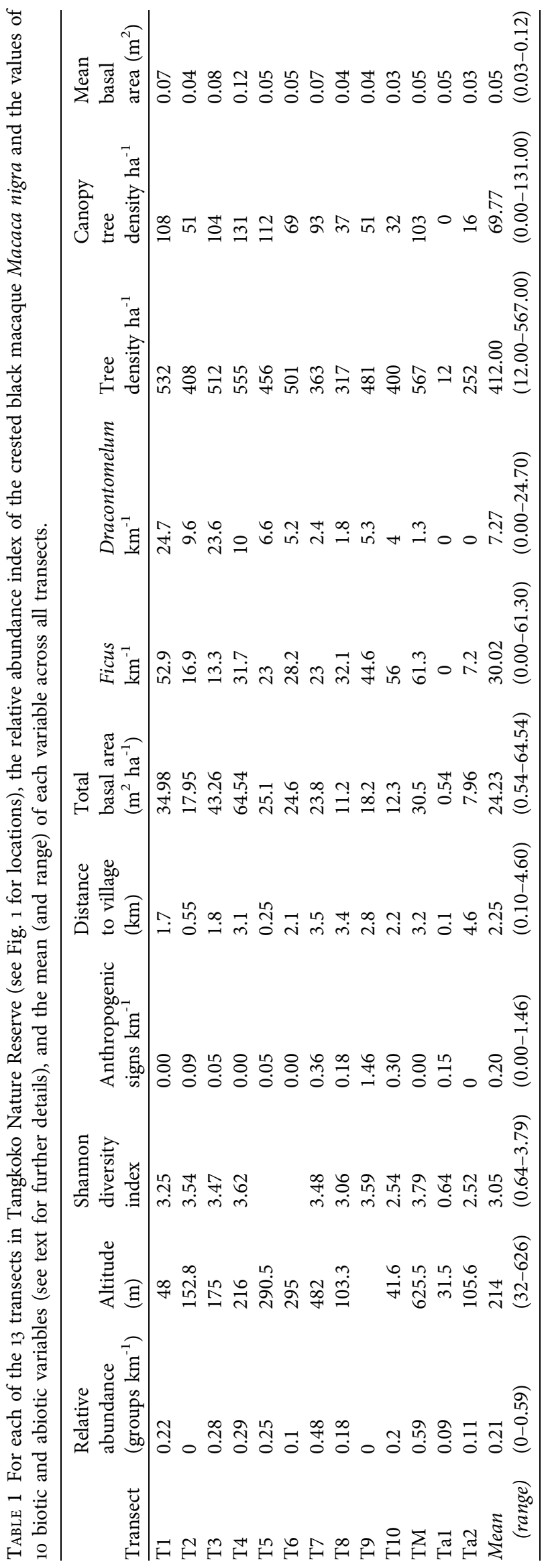

17.1), with groups comprising habituated macaques being the largest. The total population in the 4,460-ha Tangkoko Reserve was estimated to be 1,951 individuals (95\% confidence interval CI, 1,113-3,421) with a density of $44.9 \mathrm{~km}^{-2}$ (95\% CI, 25.6-78.8). Expected group size was 16.7 (95\% CI 11.9-23.4), with group density being $2.6 \mathrm{~km}^{-2}$ (95\% CI 1.6-4.3). The density estimate was $35 \%$ lower than that reported for 1994 (Rosenbaum et al., 1998) but the difference was not significant at the $5 \%$ level $(z=1.242, \mathrm{n}=2$, one-tailed $\mathrm{P}=0.107)$. The component percentages of variance of the density estimate were: encounter rate $(58.8 \%)$, group size (35.5\%) and detection probability (5.4\%).

\section{Vegetation}

A total of 1,798 individual trees belonging to 173 species were recorded in the vegetation plots, 16 of which could not be identified. Compared to those in forests, transects in burned areas ( $\mathrm{Ta} 1$ and $\mathrm{Ta} 2$ ) had lower values for almost all measured variables (Table 1). There was considerable between-transect variation in the vegetation within the forest: total basal area ranged from $11.2 \mathrm{~m}^{2} \mathrm{ha}^{-1}$ (transect 8) to $64.54 \mathrm{~m}^{2} \mathrm{ha}^{-1}$ (4). Canopy tree density ranged from 32 trees ha ${ }^{-1}$ (T10) to 131 trees $\mathrm{ha}^{-1}\left(\mathrm{~T}_{4}\right)$. Mean distance between transect and nearest village was $2.25 \mathrm{~km}$ (range $0.10-4.60 \mathrm{~km}$ ).

\section{Relationship between macaque abundance and other variables}

Macaque relative abundance correlated positively with three of the measured variables: total tree basal area, canopy tree density and mean tree basal area (Table 2). Although not significant at the $5 \%$ level, fewer canopy trees were found on transects with a higher anthropogenic disturbance index (Table 2). The multiple regression model explained $50 \%\left(R^{2}\right)$ of the variation in macaque abundance but was not significant at the $5 \%$ level $(\mathrm{P}=0.081)$. However, when excluding transect $\mathrm{T}_{9}$ from the analysis (an outlier in terms of relative abundance and anthropogenic disturbance), the model explained $68 \%\left(R^{2}\right)$ of macaque abundance and was significant $(\mathrm{P}<0.02)$.

\section{Discussion}

This is the first survey of crested macaques in the Tangkoko Nature Reserve using systematic sampling. The results suggest that the density of $M$. nigra has decreased since the last survey in 1994 (Rosenbaum et al., 1998) and, based on a linear projection of densities from the previous two surveys, that the population could become extinct within 40-50 years. Although our density estimate was 35\% lower than that of Rosenbaum et al. (1998) the difference was not significant, primarily because of the high variation in encounter rate in our study, reflecting the wide range of 


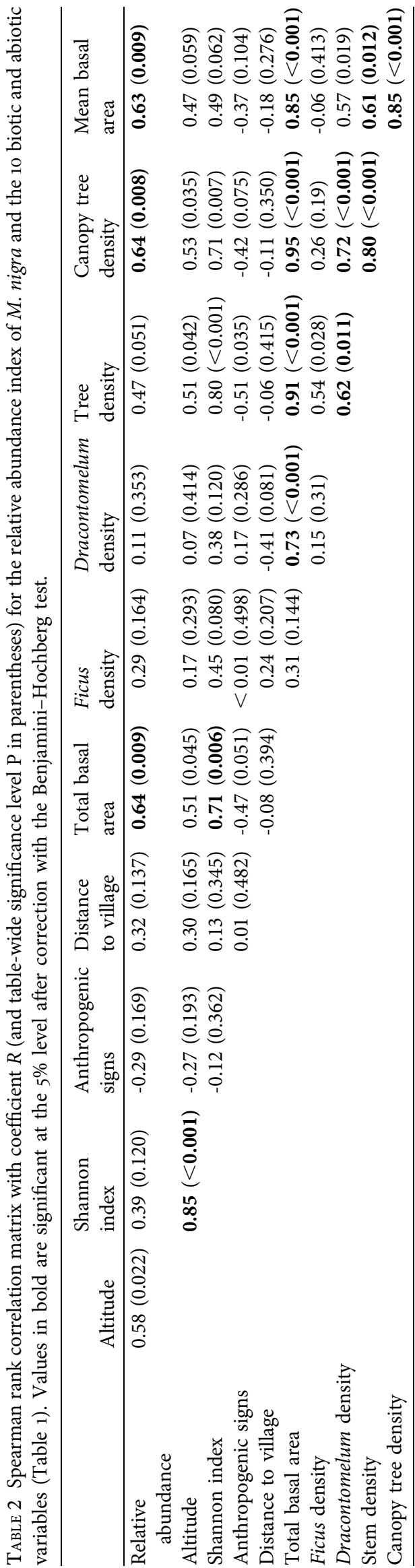

habitats (and macaque abundances) covered. In addition, Rosenbaum and colleagues may have underestimated population size because of their use of a fixed strip width of $50 \mathrm{~m}$ either side of the transect and assumption of a $100 \%$ detection probability within this distance. Application of a 50-m fixed strip width to our data, however, results in a detection probability of $74 \%(\mathrm{CV}=16.98 \%)$. A corrected density estimate of the data presented by Rosenbaum et al. (1998) would thus be 91.5 individuals $\mathrm{km}^{-2}$ (cf our result of 44.9 individuals per $\mathrm{km}^{2}$ ). Collectively, these data indicate there has been a further decline in the crested macaque population in Tangkoko since the 1994 survey.

We do not have estimates of the density of $M$. nigra in the adjacent Duasudara and Batuangus Nature Reserves but in our reconnaissance walks there we found major signs of human disturbance and did not encounter M. nigra, suggesting these areas hold only a small proportion of the total population of this protected area complex, as reported in the 1994 survey (Rosenbaum et al., 1998).

In general, macaques are highly adaptable and are found in more climates and habitats than other primate taxa (Rowe, 1996). However, even though macaques seem to be able to cope with human disturbance, previous studies in Tangkoko suggest that $M$. nigra prefers intact compared to disturbed forests (O'Brien \& Kinnaird, 1997; Rosenbaum et al., 1998). In our study altitude, canopy tree density and mean basal area collectively accounted for $68 \%$ of the variation in macaque relative abundance. That mean basal area correlates with crested macaque abundance is not surprising, as this measurement is related to potential food tree availability. However, canopy tree density may be even more important in this respect, as M. nigra seems to depend on large-sized canopy trees not only for food but also for sleeping (O’Brien \& Kinnaird, 1997). Furthermore, macaque diet is mainly composed of fruits $(66 \%)$, and large trees usually produce more extensive fruit patches than small trees (Chapman et al., 1992). Thus, large canopy trees are a more reliable food source, especially for primates living in large groups (Kinnaird \& O’Brien, 2005). Dependence on large canopy trees may explain why crested macaques prefer primary to secondary forest (O'Brien \& Kinnaird, 1997); canopy tree density also affects the abundance of other frugivorous primates (Felton et al., 2003).

The lack of a significant correlation between the abundance of macaques and that of Dracontomelum or Ficus could be because all trees above $10 \mathrm{~cm} \mathrm{DBH}$ were considered, whereas understorey and mid-canopy figs are known to contribute much less to macaque diet than large canopy figs (O'Brien \& Kinnaird, 1997) and thus these small trees might have masked the correlation.

Accessibility to the forest may lead to increased human disturbance (Hill et al., 1997; Cowlishaw \& Dunbar, 2000) and as both logging and hunting are major threats to M. nigra in Tangkoko (Lee, 1997; Rosenbaum et al., 1998), 
we would have expected a negative relationship between macaque abundance and our disturbance index and a positive relationship between abundance and distance to villages. This was not the case. In the first instance, disturbance level could have been underestimated because of difficulties in detecting signs of human presence whilst cutting transects and surveying primates, although indirect effects of illegal logging inside the Reserve may still have affected overall macaque densities by decreasing availability of food and sleeping trees. The absence of a significant relationship between macaque abundance and distance to village may be explained by the fact that we measured nearest straight line distances without taking topography and terrain complexity into account, and/ or that the small size of Tangkoko may effectively make it accessible from anywhere outside the Reserve.

During the course of our study we witnessed both hunting and illegal logging on several occasions. Illegal logging mainly took place close to the village of Kasawari but was also seen near the village of Duasudara. Hunting was also seen on at least two occasions close to Kasawari. It is very likely that some villages are more engaged in illegal activities within the Reserve than others, particularly as some benefit much less from tourism than others.

One side-effect of human disturbance may be an increase in frequency of forest fires. Removal of one timber tree often results in the creation of wide trails, making habitats more flammable (Cochrane \& Schulze, 1998). For example, drought-tolerant forests lose their resistance to fire as logging operations perforate the forest canopy, increase the fuel load on the forest floor, and allow sunlight to heat and dry the forest interior (Nepstad et al., 1998). In Tangkoko, forest fires have led to large open areas that are being covered by fastgrowing alang-alang Imperata cylindrica and plants introduced to Sulawesi (Kinnaird \& O'Brien, 1998). These areas are less suitable for macaques and abundance of $M$. nigra in these areas was found to be very low.

Our results provide evidence that human disturbance not only affects macaque abundance and distribution but also possibly group size. While habituated groups, which are followed by researchers daily and are thus less vulnerable to hunting, usually comprise 40-100 individuals (O’Brien \& Kinnaird, 1997; Neumann et al., 2010; Macaca Nigra Project, unpubl. data), none of the non-habituated groups encountered during our survey were of comparable size. Although unhabituated macaques can be more cryptic, more wary, give alarm calls and move in response to detection of an observer, all of which may affect the estimation of group size, the fact that we repeatedly saw the same small groups in the same areas suggests that in Tangkoko nonhabituated groups are smaller than habituated groups. The consistently lower sizes of non-habituated groups suggests that these social groups are smaller, possibly because of the disruptive effect of hunting (Watanabe, 1981; Gadsby, 1990; Pedersen \& Topp-Jørgensen, 2000).
Despite a continued decline, our results indicate there is still a substantial population of M. nigra in Tangkoko. This is probably the largest population within the species' natural range (Rosenbaum et al., 1998; Melfi, 2010) and, although other sizeable populations may exist in the Pinolosian region and possibly also in the eastern part of Bogani Nani Wartabone National Park (southern North Sulawesi; J. Tasirin, pers. comm.), further surveys are needed to confirm this. Additional small and scattered populations may also survive in other forest fragments (Melfi, 2010; J. Tasirin, pers. comm.). The only other significant population of M. nigra is that on Bacan Island but this was introduced by humans in 1867 and is completely outside the species' original range (Rosenbaum et al., 1998).

Although the Tangkoko population of M. nigra may still be relatively large, the observed declines over the previous 3 decades indicate that increased conservation efforts are required for this species, and we make several recommendations. Firstly, an intensive conservation education programme needs to be implemented in the five villages surrounding Tangkoko-Batuangus/Duasudara Nature Reserves, in collaboration with local schools, guides, authorities and researchers to disseminate knowledge on the importance of forest protection and environmental awareness. Secondly, solutions for smallholders relying on illegal activities within the reserve complex need to be sought to reduce pressure on the forest. This could potentially be achieved by introduction of economically viable agroforestry practices (e.g. intercropping in coconut farms) in the villages surrounding the Reserves. Thirdly, strict enforcement of existing laws and the continued commitment of BKSDA (Department for the Conservation of Natural Resources) officials and rangers to patrol the Reserve effectively is vital to limit the negative impact of hunting and illegal activities.

Fourthly, we suggest that benefits from tourism should be more equally distributed over all villages adjacent to the Reserve. The village of Kasawari, from where illegal activities have led to increased forest degradation and low macaque abundance, is of particular importance. The development of ecotourism in Kasawari could help limit the growth in tourist numbers to Batu-Putih (the village currently benefiting most from tourism) whilst increasing economic opportunities for the inhabitants of Kasawari and reducing their dependence on forest resources. A cooperation between Kasawari village and diving resorts on Lembeh Island, offering tourists combined diving and forest visits, could help attract tourists to the village. However, as ecotourism can have negative effects on primate behaviour in Tangkoko (Kinnaird \& O'Brien, 1996) this would need to be carefully managed. Tourist guides would need to be instructed to ensure safe interactions between macaques and tourists.

Apart from the authorities responsible for the management of the protected areas in which crested macaques 
occur, there are already a number of activists and nongovernmental organizations in north Sulawesi working to conserve this species using awareness campaigns, environmental education and research (Macaca Nigra Project, Selamatkan Yaki, the Wildlife Conservation Society, the Mathilde Chanvin project, and Tasikoki Wildlife Rescue Centre). Nevertheless, much work is still needed if attitudes towards forest utilization and wildlife are to change sufficiently to secure a long-term future for M. nigra.

\section{Acknowledgements}

We gratefully acknowledge the permission of the Ministry of Science and Technology (RISTEK), Directorate General of Forest Protection and Nature Conservation (PHKA), to work in the Tangkoko-Batuangus Nature Reserve. We thank BKSDA, Manado, in particular Pak Untung and Pak Yunus, for logistical support in the field, Dr Rinekso Soekmadi from the International Program of the Bogor Agricultural University (IPB) and IPB, the Macaca Nigra Project team and all assistants for help with data collection (Pak Ara Nehlman, Nadsun, Ferdy, Esly, Arcos, Liong, and Dion), Dr John Tasirin for his comments on the distribution of macaques in north Sulawesi, and N. Kakauhe and staff at Bogor Botanical Gardens for identification of tree species. MW is currently supported by a grant from the Volkswagen Foundation, Germany, and AE received funding through the German Research Council (DFG EN 719/2).

\section{References}

Benjamini, Y. \& Hochberg, Y. (1995) Controlling the false discovery rate: a practical and powerful approach to multiple testing. Journal of the Royal Statistical Society, Series B, 57, 289-300.

Buckland, S.T., Anderson, D.R., Burnham, K.P., Laake, J.L., Borchers, D.L. \& Thomas, L. (2001) Introduction to Distance Sampling: Estimating Abundance of Biological Populations. Oxford University Press, New York, USA.

Bynum, D.Z., KohlhaAs, A.K. \& Pramono, A.H. (1999) Conservation status of Sulawesi macaques. Tropical Biodiversity, 6, 123-144.

Chapman, C.A., Chapman, L.J., Wrangham, R., Hunt, K., GEBO, D. \& GARDNER, L. (1992) Estimators of fruit abundance of tropical trees. Biotropica, 24, 527-531.

Chapman, C.A. \& Peres, C.A. (2001) Primate conservation in the new millennium: the role of scientists. Evolutionary Anthropology, $10,16-33$.

Cochrane, M.A. \& Schulze, M.D. (1998) Forest fires in the Brazilian Amazon. Conservation Biology, 12, 948-950.

Cowlishaw, G. \& Dunbar, R. (2000) Primate Conservation Biology. The University of Chicago Press, Chicago, USA.

Felton, A.M., Engström, L.M., Felton, A. \& Knott, C.D. (2003) Orang-utan population density, forest structure and fruit availability in hand-logged and unlogged peat swamp forests in West Kalimantan, Indonesia. Biological Conservation, 114, 91-101.

Fooden, J. (1969) Taxonomy and Evolution of the Monkeys of Celebes. Karger, Basel, Switzerland.
Gadsby, E.L. (1990) The status and distribution of the drill, Madrillus leucophaeus, in Nigeria. A report focusing on hunters and hunting and their threat to remaining populations of drills and other forest primates in southeast Nigeria. Unpublished report to WCI, WWF-US, and the Nigerian government.

Grow, N., Gursky-Doyen, S. \& Supriatna, J. (2010) Introduction. In Indonesian Primates (eds S. Gursky-Doyen \& J. Supriatna), pp. 1-6. Springer, New York, USA.

Hill, K., Padwe, J., Bejyvagi, C., Bepurangi, A., Jakugi, F., Tyкuarangi, R. \& TyкuARangi, T. (1997) Impact of hunting on large vertebrates in the Mbaracayu Reserve, Paraguay. Conservation Biology, 11, 1339-1353.

IUCN (1991) Atlas of Tropical Rainforest. IUCN, Gland, Switzerland. IUCN (2010) IUCN Red List of Threatened Species v. 2010.4. Http:// www.iucnredlist.org [accessed 10 June 2010].

Kinnaird, M.F. \& O'Brien, T.G. (1996) Ecotourism in the Tangkoko DuaSudara Nature Reserve: opening Pandora's box? Oryx, 30, 65-73.

Kinnaird, M.F. \& O'Brien, T.G. (1998) Ecological effects of wildfire on lowland rainforest in Sumatra. Conservation Biology, 12, 954-956.

Kinnaird, M.F. \& O'Brien, T.G. (2005) Fast foods of the forest: the influence of figs on primates and hornbills across Wallace's line. In Tropical Fruits and Frugivores (eds J.L. Dew \& J.P. Boubli), pp 155-186. Springer, Dordrecht, The Netherlands.

LEE, R.J. (1997) The impact of hunting and habitat disturbance on the population dynamics and behavioural ecology of the crested black macaque (Macaca nigra). PhD thesis, University of Oregon, Oregon, USA.

Leighton, M. \& Leighton, D.R. (1982) The relationship of size and feeding aggregate to size of food patch: howler monkey Alouatta palliate feeding in Trichilia cipo trees on Barro Colorado Island. Biotropica, 14, 81-90.

MacKinnon, J. \& MacKinnon, K. (1980) Cagar Alam Gunung Tangkoko-DuaSudara, Sulawesi Utara Management Plan 1981-1986. Bogor, Indonesia.

Marsh, C.W., Johns, A.D. \& Ayres, J.M. (1987) Effects of habitat disturbance on rain forest primates. In Primate Conservation in the Tropical Rain Forest (eds C.W. Marsh \& R.A. Mittermeier), pp 83-107. Alan R. Liss, New York, USA.

Melfi, V. (2010) Selamatkan Yaki! conservation of Sulawesi crested black macaques, Macaca nigra. In Indonesian Primates (eds S. Gursky-Doyen \& J. Supriatna), pp 343-356. Springer, New York, USA.

Nepstad, D., Moreira, A., Veríssimo, A., Lefebvre, P., Schlesinger, P., Potter, C. et al. (1998) Forest fire prediction and prevention in the Brazilian Amazon. Conservation Biology, 12, 951-953.

Neumann, C., Assahad, G., Hammerschmidt, K., Farajallah, D.P. \& Engelhardt, A. (2010) Loud calls in male Macaca nigra - a signal of dominance in a tolerant primate species. Animal Behaviour, 79, 187-193.

Noss, R.F. \& Csuti, B. (1994) Habitat fragmentation. In Principles of Conservation Biology (eds G.K. Meffe \& C.R. Carroll), pp. 237264. Sinauer Associates, Sunderland, USA.

O'Brien, T.G. \& Kinnaird, M.F. (1996) Changing populations of birds and mammals in North Sulawesi. Oryx, 30, 150-156.

O’Brien, T.G. \& Kinnaird, M.F. (1997) Behavior, diet and movements of the Sulawesi crested black macaque (Macaca nigra). International Journal of Primatology, 18, 321-351.

O'Brien, T.G. \& KinNaird, M.F. (2000) Differential vulnerability of large birds and mammals to hunting in North Sulawesi, Indonesia, and the outlook for the future. In Hunting for 
Sustainability in Tropical Forests (eds J.G. Robinson \& E.L. Bennett), pp. 199-213. Columbia University Press, New York, USA.

Onderdonk, D.A. \& Chapman, C.A. (2000) Coping with forest fragmentation: the primates of Kibale National Park, Uganda. International Journal of Primatology, 21, 587-611.

Pedersen, U.B. \& Topp-Jørgensen, J.E. (2000) The impact of hunting on three primate species in Udzungwa Mountains, Tanzania. MSc thesis, University of Copenhagen, Copenhagen, Denmark.

Peres, C.A. (1990) Effects of hunting on western Amazonian primate communities. Biological Conservation, 54, 47-59.

Peres, C.A. (1999) General guidelines for standardizing line-transect surveys of tropical forest primates. Neotropical Primates, 7, 11-16.

Rosenbaum, B., O’Brien, T., Kinnaird, M. \& Supriatna, J. (1998) Population densities of Sulawesi crested black macaques (Macaca nigra) on Bacan and Sulawesi, Indonesia: effects of habitat disturbance and hunting. American Journal of Primatology, 44, 89-106.

Rovero, F. \& Struhsaker, T. (2007) Vegetative predictors of primate abundance: utility and limitations of a fine-scale analysis. American Journal of Primatology, 69, 1242-1256.

Rowe, N. (1996) The Pictorial Guide to the Living Primates. Pogonia Press, East Hampton, USA.

Sugardjito, J., Southwick, C.H., Supriatna, J., Kohlhaas, A., BAKer, A., Erwin, J. et al. (1989) Population survey of macaques in northern Sulawesi. American Journal of Primatology, 18, 258-301.

Supriatna, J., \& Andayani, N. (2008) Macaca nigra. In IUCN Red List of Threatened Species. Http://www.iucnredlist.org [accessed 18 June 2010].
Thomas, L., Buckland, S.T., Rexstad, E.A., LaAke, J.L., Strindierg, S., Hedley, S.L., et al. (2010) Distance software: design and analysis of distance sampling surveys for estimating population size. Journal of Applied Ecology, 47, 5-14.

Watanabe, K. (1981) Variations in group composition and population density of the two sympatric Mentawaian leaf-monkeys. Primates, 22, 145-160.

Whitten, A., Mustafa, M. \& Henderson, G. (1987) The Ecology of Sulawesi. Oxford University Press, Oxford, UK.

\section{Biographical sketches}

Juan Francisco Gallardo Palacios is currently involved in an ecological research project on the red colobus of Udzungwa, Tanzania. He has interests in conservation of primates and social work. ANTJE ENGELHARDT has research interests in primate sexual selection and currently runs the field research station in Tangkoko Nature Reserve, where she studies M. nigra reproduction and behaviour. MUH A M M AD A GIL is a veterinarian involved in Indonesian wildlife conservation. Keith Hodges has research interests in evolutionary endocrinology, comparative reproduction and primate conservation. ROGER BOGIA has been involved in several projects on $M$. nigra in north Sulawesi and has recently started to work as a wildlife photographer. MATTHIAS WALTERT studies the effects of forest land use on tropical biodiversity and teaches wildlife population and biodiversity assessment on the integrated bi-national MSc International Nature Conservation at Georg-August-University Göttingen, Germany, and Lincoln University, New Zealand. 